Journal Club

Editor's Note: These short, critical reviews of recent papers in the Journal, written exclusively by graduate students or postdoctoral fellows, are intended to summarize the important findings of the paper and provide additional insight and commentary. For more information on the format and purpose of the Journal Club, please see http://www.jneurosci.org/misc/ifa_features.shtml.

\title{
Insights into the Role of Postsynaptic cJun and CREB2 in Persistent Long-Term Synaptic Facilitation
}

\author{
Patrick K. McCamphill ${ }^{1}$ and Margaret H. Hastings ${ }^{2}$ \\ ${ }^{1}$ Department Neurology and Neurosurgery and 2Department of Psychology, Montreal Neurological Institute, McGill University, Montreal, QC, H3A 2B4, \\ Canada \\ Review of Hu et al.
}

Lasting changes in synaptic strength are believed to be the principal means of memory storage in the nervous system. The establishment of persistent synaptic changes underlying long-term memory requires new gene expression, as indicated by the finding that inhibition of transcription blocks formation of various types of long-term, but not short-term, memory (Alberini, 2009).

Key insights into transcriptional events underlying long-term memory formation have come from study of sensitization of the defensive withdrawal reflex in the mollusk Aplysia californica. Release of serotonin (5HT) after tail shock causes long-term facilitation (LTF) of the sensory-motor synapse, resulting in long-lasting sensitization of the defensive response (Kandel, 2001). Aplysia's large sensory and motor neurons can be identified morphologically, isolated, and cocultured. The neurons form synapses in culture, and it is possible to reproduce the synaptic facilitation that underlies reflex sensitization by treating cultures with 5-HT. With this preparation, it is also possible to restrict manipulations to the presynaptic or postsynaptic neuron by microinjection.

Received March 7, 2015; revised April 7, 2015; accepted April 13, 2015.

M.H.H. is supported by the Fonds de Recherche Santé Québec. We thank to Dr. Wayne Sossin and Dr. Ken Hastings for helpful comments.

The authors declare no competing financial interests.

Correspondence should be addressed to Margaret H. Hastings, 3801

University Street, Rm. BT105, Montreal, QC, H3A 2B4, Canada. E-mail: margaret.hastings@mail.mcgill.ca

DOI:10.1523/JNEUROSCI.0897-15.2015

Copyright $\odot 2015$ the authors $\quad 0270-6474 / 15 / 358039-03 \$ 15.00 / 0$
This targeted approach has proven instrumental in elucidating transcriptional mechanisms of long-term synaptic plasticity.

Seminal studies in Aplysia established the transcription factor cAMP response element binding protein (CREB) as a critical mediator of transcriptional changes underlying long-term synaptic plasticity. In the first paper implicating CREB in memory, presynaptic injection of oligonucleotides encoding the cAMP response element (CRE) blocked long-term but not short-term facilitation at the Aplysia sensory-motor neuron synapse (Dash et al., 1990). CREB activity in the sensory neuron was later found to be required and sufficient for LTF (Bartsch et al., 1995).

After this, a flurry of research established CREB as an evolutionarily conserved modulator of gene expression during long-term memory consolidation. Like facilitation in Aplysia, long-term potentiation (LTP) in the rodent hippocampus, a model for memory, was found to have an early, transcription-independent phase and a late, transcription-dependent phase (Barco et al., 2006). Induction of late-LTP activated CREB (Bito et al., 1996; Deisseroth et al., 1996), while partial CREB knock-out impaired late-LTP and memory in mouse (Bourtchuladze et al., 1994). Transcription-independent earlyLTP in the CA1 region of the hippocampus is generally accepted to result from an increase in the activity and number of postsynaptic AMPA receptors (Granger and Nicoll, 2014), and AMPA receptor trafficking has also been implicated in late-LTP (Sacktor, 2011). However, it has not been resolved whether transcriptional regulation occurs postsynaptically, presynaptically, or both, during late-LTP. One reason for this is that it is technically challenging to target manipulations specifically to one side of the synapse within the rodent brain. While hippocampal subregion-specific gene knock-out has been accomplished, it has not yet been applied to this problem (Tsien et al., 1996).

In addition to CREB, other transcription factors sharing the basic Leucine Zipper Domain (bZIP) characteristic of CREB have also been implicated in memory. Work in Drosophila showed that different bZIP transcription factors activate or repress memory (Yin et al., 1994, 1995). Likewise, in Aplysia, presynaptic inhibition of the bZIP transcription factor CREB2 enhanced LTF, consistent with CREB2 acting as a suppressor of facilitation (Bartsch et al., 1995). In addition, CREB not only mediates important transcriptional changes but is itself transcriptionally regulated (Rajasethupathy et al., 2012). Thus, bZIP transcription factors can be positive or negative regulators of synaptic strength and are highly regulated themselves.

Although facilitation in Aplysia was initially thought to rely exclusively on presynaptic mechanisms, postsynaptic events are now known to contribute as well. LTF involves new synapse formation and postsynaptic restructuring (Glanzman et al., 1989; Li et al., 2009). Furthermore, LTF 
can be disrupted by postsynaptic calcium chelation or protein synthesis inhibition (Cai et al., 2008). However, in contrast to LTP in rodents, for which the postsynaptic mechanisms have been intensively studied, there is still much less known about the postsynaptic mechanisms of LTF in Aplysia.

While transcriptional regulation in the presynaptic sensory neuron during LTF is well documented, Hu et al. (2015) asked whether transcriptional changes in the postsynaptic motor neuron also contribute. They investigated CREB1, CREB2, and cJun, three bZIP transcription factors that mediate transcriptional modulation in the presynaptic cell during LTF (Kandel, 2001). Interestingly, when $\mathrm{Hu}$ et al. (2015) measured changes in mRNA levels of CREB1, CREB2, and cJun in the postsynaptic neuron $48 \mathrm{~h}$ after induction of persistent LTF, the changes they noted differed from those previously observed in the presynaptic neuron during LTF. Earlier reports found that CREB1 expression in the presynaptic neuron increased and CREB2 decreased during LTF, whereas Hu and colleagues (2015) report an increase in CREB2 and cJun mRNA in the postsynaptic neuron, with no change in CREB1. This difference suggests LTF may involve differential regulation of transcription presynaptically and postsynaptically.

Hu et al. (2015) next explored the effects of postsynaptic overexpression of CREB2 and cJun on synaptic strength. While neither altered basal synaptic strength when overexpressed individually, coexpression of the two produced persistent enhancement that phenocopied 5-HT-induced LTF. This result is significant as it demonstrates that purely postsynaptic transcriptional modulation is sufficient to induce lasting facilitation. In contrast to the facilitating effect of postsynaptic overexpression, $\mathrm{Hu}$ et al. (2015) found CREB2 and cJun coexpression in the presynaptic sensory neuron decreased basal synaptic strength.

Together, these data highlight the context dependence of transcription factor function. While presynaptic CREB2 impedes LTF, upregulation of postsynaptic CREB2 contributes to LTF. Thus, transcription factors can have opposite roles in plasticity depending on whether they are acting presynaptically or postsynaptically. Extrapolated to the more complex neural networks in the mammalian brain, where most neurons have both presynaptic and postsynaptic roles, this observation raises an intriguing question. Are the presynaptic and postsynaptic functions of a neuron in direct competition with one another? In other words, do high CREB2 levels favor a predominantly postsynaptic role for the cell, while low CREB2 levels favor a more presynaptic role?

Since postsynaptic coexpression of CREB2 and cJun caused persistent LTF, Hu and colleagues (2015) decided to test whether postsynaptic expression of CREB2 or cJun on its own would lower the threshold for conversion of transient LTF into persistent LTF. The transient form of LTF is produced by a single course of 5-HT treatment, whereas persistent LTF requires two sequential treatments. Although basal synaptic strength was unaffected, overexpression of either CREB2 or cJun alone, but not CREB1, was sufficient to cause persistent LTF with only a single session of 5-HT treatment (Hu et al., 2015). Overexpression of CREB2 or cJun in the postsynaptic neuron is therefore sufficient to prolong LTF.

Finally, Hu et al. (2015) confirmed the necessity for postsynaptic bZIP transcription factors in persistent LTF by showing that long-lasting facilitation does not occur when cJun is inhibited. Overexpression of a cJun dominant-negative in the motor neuron reduced the duration of LTF induced by two sequential 5-HT treatments, resulting in transient LTF comparable to that produced by a single round of 5-HT. This suggests transcriptional regulation in the postsynaptic cell is indeed a critical part of the mechanism of LTF.

These findings invite several questions. First, what are the genes whose transcription is modulated by CREB2 and cJun? In rodents, late-LTP is known to require CREB-mediated transcriptional upregulation of the neurotrophic factor BDNF, postsynaptic proteins such as Arc, and transcription factors like c-fos and Zif268 that, in turn, modulate expression of other downstream effectors (Cortés-Mendoza et al., 2013). Yet, how these diverse and multistep transcriptional changes culminate in lasting enhancement of synaptic strength remains uncertain. It would be fascinating to determine whether the homologous genes are upregulated postsynaptically during LTF in Aplysia. Given that LTF involves new synapse formation, postsynaptic components such as glutamate receptors and transsynaptic and scaffolding proteins are also possible candidates, as are molecules involved in glutamate receptor trafficking. Hu et al. (2015) propose to address these questions with future experiments investigating changes in gene expression in the postsynaptic neuron during LTF.

Other important questions concern the apparently synergistic relationship between CREB2 and cJun. Do these transcription factors act on the same or different target genes? Are they acting independently or as a heterodimer? Does one factor function upstream of the other? Levels of overexpressed CREB2 protein were dramatically increased by coexpression with cJun, and vice versa (Hu et al., 2015), suggesting the factors may heterodimerize, stabilizing one another. Headway might be made on these questions by first determining with a dominantnegative whether postsynaptic CREB2 is required for persistent LTF, as cJun is. Rescue experiments combining expression of dominant-negative and wild-type forms of CREB2 and cJun during LTF could then be used to determine whether one acts upstream of the other.

The interpretation of Hu et al.'s (2015) results is complicated by the fact that the persistent LTF protocol used to investigate postsynaptic transcriptional mechanisms differs from the transient LTF protocol used in all previous studies characterizing transcription at this synapse. Work with both rodents and Aplysia has demonstrated that different induction protocols can produce mechanistically distinct forms of synaptic enhancement (Mauelshagen et al., 1998; Panja and Bramham, 2014). For these reasons, future experiments should confirm that the patterns of presynaptic transcription characteristic of the conventional LTF also occur during persistent LTF. Likewise, it will be important to determine whether the postsynaptic changes elucidated during persistent LTF also occur in transient LTF induced by the conventional protocol.

Nevertheless, the results of $\mathrm{Hu}$ et al. (2015) demonstrate the insights to be gained by studying plasticity at the level of individual neurons in a circuit. The opposing effects of CREB2 and cJun on synaptic strength in the presynapse and postsynapse would likely have been missed if a less targeted manipulation had been used. These findings highlight the need for more directed presynaptic and postsynaptic manipulations in rodents to resolve long-standing questions about the locus of cellular changes underlying LTP. This is particularly true as many memory mechanisms identified in invertebrates are conserved in mammals, including the role of CREB-mediated transcriptional regulation. Even the context-specificity of bZIP transcription factors like CREB2 may be conserved, as Liu et al. (2014) found that disruption of the rat CREB2 ortholog, ATF4, 
traditionally considered a memory suppressor gene (Chen et al., 2003), decreased the density of postsynaptic structures in the hippocampus, suggesting a positive role in memory. Thus, it seems likely that in mammals, as in Aplysia, the role of transcriptional regulation in synaptic plasticity is complex, and the activity of the same transcription factor might affect presynaptic and postsynaptic functions in different and even opposite ways.

\section{References}

Alberini CM (2009) Transcription factors in long-term memory and synaptic plasticity. Physiol Rev 89:121-145. CrossRef Medline

Barco A, Bailey CH, Kandel ER (2006) Common molecular mechanisms in explicit and implicit memory. J Neurochem 97:1520-1533. CrossRef Medline

Bartsch D, Ghirardi M, Skehel PA, Karl KA, Herder SP, Chen M, Bailey CH, Kandel ER (1995) Aplysia CREB2 represses long-term facilitation: relief of repression converts transient facilitation into long-term functional and structural change. Cell 83:979-992. CrossRef Medline

Bito H, Deisseroth K, Tsien RW (1996) CREB phosphorylation and dephosphorylation: a $\mathrm{Ca}(2+)$ - and stimulus duration-dependent switch for hippocampal gene expression. Cell 87:1203-1214. CrossRef Medline

Bourtchuladze R, Frenguelli B, Blendy J, Cioffi D, Schutz G, Silva AJ (1994) Deficient longterm memory in mice with a targeted mutation of the cAMP-responsive element-binding protein. Cell 79:59-68. CrossRef Medline

Cai D, Chen S, Glanzman DL (2008) Postsynaptic regulation of long-term facilitation in Aplysia. Curr Biol 18:920-925. CrossRef Medline

Chen A, Muzzio IA, Malleret G, Bartsch D, Ver- bitsky M, Pavlidis P, Yonan AL, Vronskaya S, Grody MB, Cepeda I, Gilliam TC, Kandel ER (2003) Inducible enhancement of memory storage and synaptic plasticity in transgenic mice expressing an inhibitor of ATF4 (CREB-2) and C/EBP proteins. Neuron 39: 655-669. CrossRef Medline

Cortés-Mendoza J, Díaz de León-Guerrero S, PedrazaAlva G, Pérez-Martinez L (2013) Shaping synaptic plasticity: the role of activity-mediated epigenetic regulation on gene transcription. Int J Dev Neurosci 31:359-369. CrossRef Medline

Dash PK, Hochner B, Kandel ER (1990) Injection of the cAMP-responsive element into the nucleus of Aplysia sensory neurons blocks long-term facilitation. Nature 345:718-721. CrossRef Medline

Deisseroth K, Bito H, Tsien RW (1996) Signaling from synapse to nucleus: postsynaptic CREB phosphorylation during multiple forms of hippocampal synaptic plasticity. Neuron 16:89-101. CrossRef Medline

Glanzman DL, Kandel ER, Schacher S (1989) Identified target motor neuron regulates neurite outgrowth and synapse formation of Aplysia sensory neurons in vitro. Neuron 3:441-450. CrossRef Medline

Granger AJ, Nicoll RA (2014) Expression mechanisms underlying long-term potentiation: a postsynaptic view, 10 years on. Philos Trans R Soc Lond B Biol Sci 369:20130136. CrossRef Medline

Hu JY, Levine A, Sung YJ, Schacher S (2015) cJun and CREB2 in the postsynaptic neuron contribute to persistent long-term facilitation at a behaviorally relevant synapse. J Neurosci 35:386-395. CrossRef Medline

Kandel ER (2001) The molecular biology of memory storage: a dialogue between genes and synapses. Science 294:1030-1038. CrossRef Medline

Li HL, Huang BS, Vishwasrao H, Sutedja N, Chen W, Jin I, Hawkins RD, Bailey CH, Kandel ER (2009) Dscam mediates remodeling of gluta- mate receptors in Aplysia during de novo and learning-related synapse formation. Neuron 61:527-540. CrossRef Medline

Liu J, Pasini S, Shelanski ML, Greene LA (2014) Activating transcription factor 4 (ATF4) modulates post-synaptic development and dendritic spine morphology. Front Cell Neurosci 8:177. CrossRef Medline

Mauelshagen J, SherffCM, Carew TJ (1998) Differential induction of long-term synaptic facilitation by spaced and massed applications of serotonin at sensory neuron synapses of Aplysia californica. Learn Mem 5:246-256. Medline

Panja D, Bramham CR (2014) BDNF mechanisms in late LTP formation: a synthesis and breakdown. Neuropharmacology 76:664676. CrossRef Medline

Rajasethupathy P, Antonov I, Sheridan R, Frey S, Sander C, Tuschl T, Kandel ER (2012) A role for neuronal piRNAs in the epigenetic control of memory-related synaptic plasticity. Cell 149:693-707. CrossRef Medline

Sacktor TC (2011) How does PKMzeta maintain long-term memory? Nat Rev Neurosci 12: 9-15. CrossRef Medline

Tsien JZ, Chen DF, Gerber D, Tom C, Mercer EH, Anderson DJ, Mayford M, Kandel ER, Tonegawa S (1996) Subregion- and cell typerestricted gene knockout in mouse brain. Cell 87:1317-1326. CrossRef Medline

Yin JC, Wallach JS, Del Vecchio M, Wilder EL, Zhou H, Quinn WG, Tully T (1994) Induction of a dominant negative CREB transgene specifically blocks long-term memory in Drosophila. Cell 79:49-58. CrossRef Medline

Yin JC, Del Vecchio M, Zhou H, Tully T (1995) CREB as a memory modulator: induced expression of a dCREB2 activator isoform enhances long-term memory in Drosophila. Cell 81:107-115. CrossRef Medline 